\title{
6. PRESERVATION OF CULTURAL HERITAGE
}

lonising radiation is increasingly used in a wide range of industrial and scientific processes, including the sterilisation of medical devices, food irradiation and polymer cross-linking. For more than 40 years industrial irradiation facilities have used gamma rays or electron beams for these purposes. In this chapter we explore applications of ionising radiation in the preservation of cultural artefacts.

\subsection{BASIC PRINCIPLES}

High energy photons or electrons can break molecular bonds, initiating further chemical reactions. The induced scission of both strands in a cell's DNA double helix is the main cause for the radiation biocide effect and the basis of applications related to "killing" unwanted pests (bacteria, fungi or insects). At the same time, care needs to be taken to prevent any unwanted degradation of the irradiated material. The desired effect is achieved by exposing items for a predetermined time in an intense radiation field.

Two irradiation processes have been used in the preservation of cultural artefacts [177-179]. In the first process, radiation treatment is used for the disinfection of insects and moulds in materials.

In addition, resins may be used to impregnate the material and consolidate its structure. Here the role of irradiation is to polymerise the resin. This second technique is especially useful for wooden artefacts. It halts further decay, but does this at the expense of changing the material's structure and properties, including mass and colour. It is irreversible.

Both techniques were initially developed using $y$-radiation. See Figure 6.1. The first experiments using

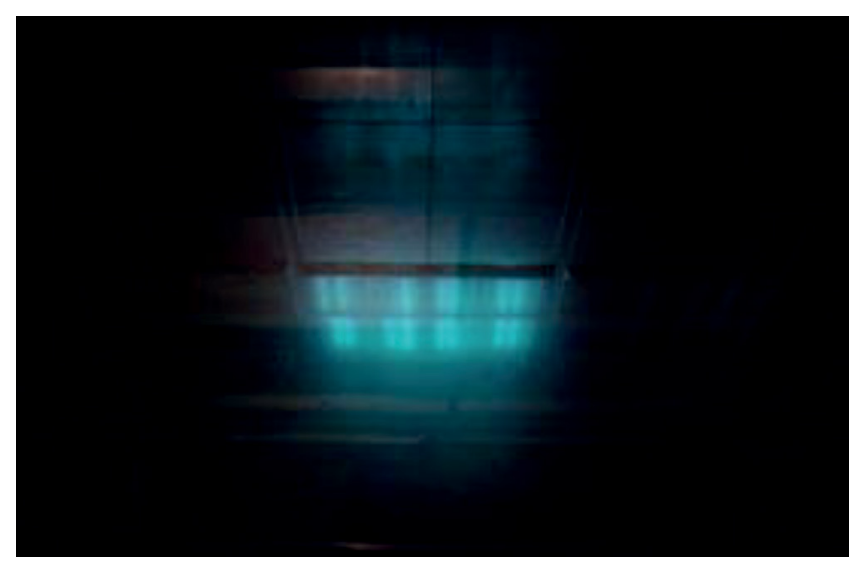

Figure 6.2: High activity ${ }^{60} \mathrm{Co}$ sources (about $500 \mathrm{kCi}$ in 2014) stored under water at the IFIN-HH (National Institute for Nuclear Physics and Engineering "Horia Hulubei", Bucharest, Romania) $y$ irradiation facility. Blue Cerenkov radiation is produced by the high energy $\beta$ particles from the ${ }^{60} \mathrm{Co}$ sources that pass through the water.

$Y$-radiation to preserve cultural artefacts were carried out more than 50 years ago [180].

Even now, $y$-radiation is the most used type of ionising radiation for cultural heritage applications. However, irradiation now also includes accelerator-produced electron beams and $\mathrm{X}$-rays. To avoid disrupting atomic nuclei in the irradiated material, electron beam energies are limited to a maximum of $10 \mathrm{MeV}$ and generated $\mathrm{X}$-rays to a maximum of $5 \mathrm{MeV}$. $y$-rays obtained from radioisotopes generally do not have high enough energies to initiate nuclear reactions.

$\gamma$-emission generally follows spontaneous $\beta$-decay of unstable nuclides. One or more photons with characteristic energies are produced in each decay event. The most widespread y source in current use is ${ }^{60} \mathrm{Co}$ (see Figure 6.2). This artificial isotope is produced on a large scale by activation of ${ }^{59} \mathrm{Co}$ in nuclear reactors. For example, CANDU reactors can produce ${ }^{60} \mathrm{Co}$ in parallel with energy production.
Figure 6.1: Spectrum of electromagnetic radiation. $\mathrm{X}$-rays and $\mathrm{Y}$-rays are ionising radiation, while radio waves, infra-red (IR), visible (VIS) and ultra-violet (UV) radiation do not have enough energy for radiation treatments.

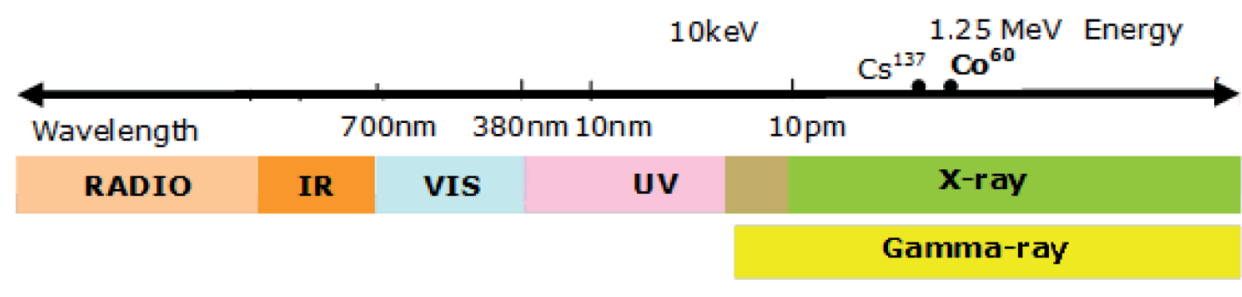




\subsection{INSTRUMENTATION OF NUCLEAR PRESERVATION METHODS}

There is considerable diversity in the design of $y$ irradiation facilities [179] but two characteristics are common: a system for controlling the exposure of irradiated items to the radiation source and shielding to protect humans and the environment from the effects of the high radiation field.

The control of the exposure time is usually achieved by temporarily shielding the radiation source in a lead or concrete containment (dry storage) or using a water pool (wet storage).

The irradiation is carried out in a dedicated room shielded by concrete walls see Figure 6.3. Small research irradiators have their irradiation chambers (cells) shielded by lead but their small size generally makes them unsuitable for the study of cultural artefacts. Industrial scale irradiators tend to have conveyor systems for transporting the goods in and out of a special irradiation room. Some cultural heritage items (paper, textiles, and books) can be loaded in standard boxes increasing the efficiency of the procedure see Figure 6.3.

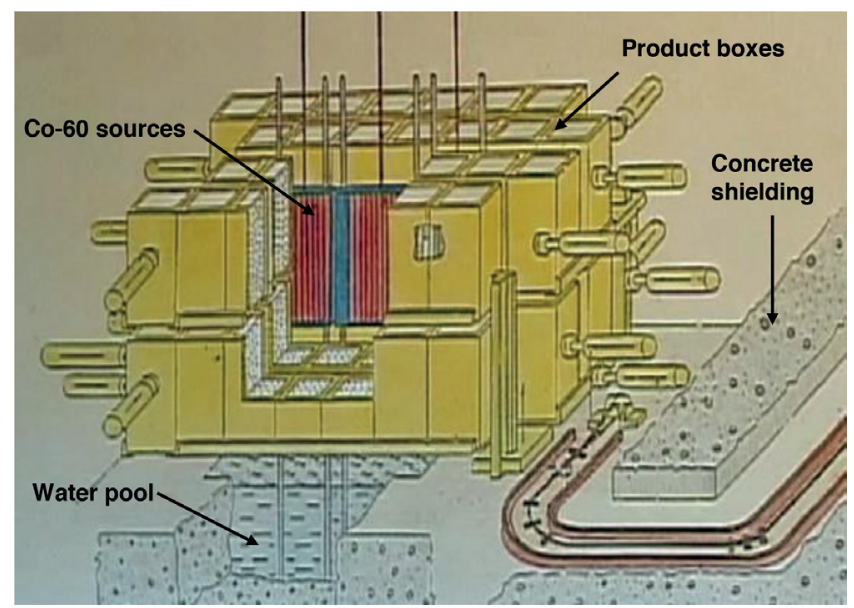

Figure 6.3: Outline of the IFIN-HH ${ }^{60} \mathrm{Co}$ irradiation facility. The concrete shielding is designed for a maximum ${ }^{60} \mathrm{Co}$ intensity of 2 million Ci. Up to $10 \mathrm{~m}^{3}$ of material can be simultaneously irradiated and an extra space is available between the source and the walls (up to $8 \mathrm{~m}^{3}$ ) which allow the irradiation of large items (e.g. large wooden icons or furniture).

For the irradiation consolidation technique some supplementary equipment is required: vacuum/ pressure chambers or impregnation baths are needed to introduce the consolidation matrix into the material being conserved prior to its irradiation [178].

\subsection{APPLICATIONS OF NUCLEAR PRESERVATION METHODS}

\subsubsection{RADIATION DISINFECTION}

Radiation resistance is normally characterised by one of two measures [179]: the so-called $\mathrm{LD}_{50}$ lethal dose (the dose equivalent which kills $50 \%$ of a certain population) or $\mathrm{D}_{10}$ (the absorbed dose which produces a $90 \%$ decrease in a population). Whereas the $L D_{50}$ lethal dose is about 10 Gy for mammals and $100 \mathrm{~Gy}$ for insects, the $\mathrm{D}_{10}$ dose for fungi and bacteria can be $1000 \mathrm{~Gy}$ or more.

Treatment by gamma irradiation: From shortly after its discovery, ionising radiation was observed to produce irreversible damage to living cells. The interaction of radiation modifies molecular structures and bio-chemical processes. Radiation resistance is large for simple organisms (bacteria, fungi) but is much lower for more complex organisms.

Strengths: $y$-rays have a high penetration into artefacts, assuring a strong biocide effect, but do not damage artefact components. The process is fast and ideal for emergency situations.

Weaknesses: The cost of $\mathrm{y}$-irradiation facilities are high, but these can be shared with medical and food irradiation. Stringent radiation protection procedures are necessary. Artefacts have to be transported to the facility.

The biocide effect of ionising radiation was first used for sterilisation of medical equipment in order to obtain materials free of any living micro-organisms. Later it was used in food irradiation to reduce populations of microorganisms or to eradicate insect pests.

These two uses led to major technological developments over the past 50-60 years and produced a large body of data on the radiation resistance of micro-organisms and insects. To a good approximation, the survival curve for a given micro-organism is observed to follow an exponential decay (See Figure 6.4). This allows the disinfection rate due to ionising radiation to be predicted.

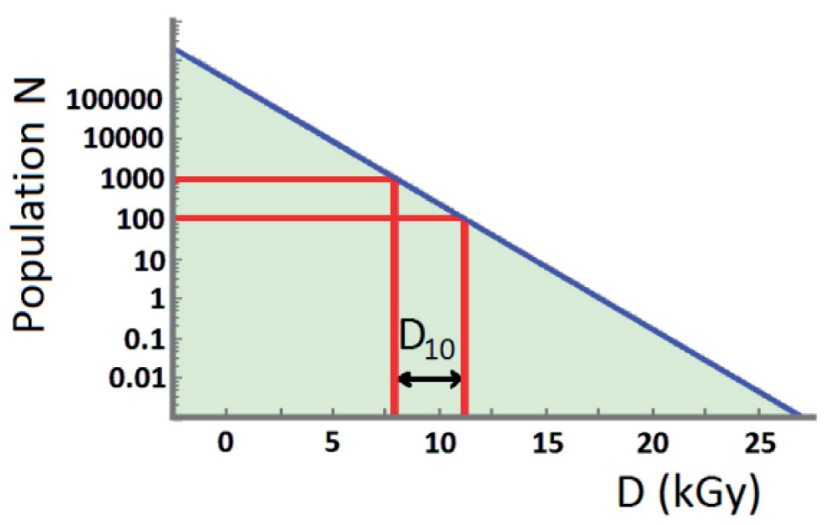

Figure 6.4: Schematic survival curve showing an exponential relation between the surviving population of a micro-organism population $\mathrm{N}$ and its absorbed radiation dose $\mathrm{D}$. $\mathrm{D}_{10}$ is the absorbed dose which produces a $90 \%$ decrease in a population. 
Many cultural heritage items are threatened by biological attacks. The organic constituents (cellulose, collagen or proteins) are sources of food for microorganisms and insects. Improper storage conditions lead to active attacks even in museums, archives or libraries. Such attacks are difficult to stop or eradicate because of the large quantities of items involved. Conservators and restorers can easily treat individual items but the mass treatment of collections is problematic.

Methods involving fumigation, liquid chemicals or anoxic atmospheres have their own particular advantages and disadvantages in terms of efficacy and efficiency which we will not detail. Rather we will focus on gamma radiation treatment, in which the high penetration of ionising radiation assures the required biocide effect.

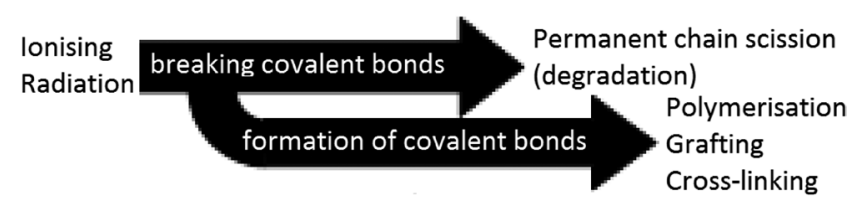

Figure 6.5: The contrasting effects of ionising radiation on macro-molecules.

\section{Wood}

Wooden artefacts are commonly affected by woodworm or wood-boring beetle infestations. The radiation resistance of insects is relatively low and these pests are easily eliminated by irradiation, regardless of their stage of development (larvae, eggs). Fungi are inactivated at higher irradiation doses, which are well tolerated by wood. Despite the fact that cellulose is known to be degraded by irradiation, the lignin-cellulose assembly shows no changes when subjected to a large dose. If wood is painted, there is a question as to the extent to which the pigments or varnish of the artwork are affected by radiation. In the literature there are reports on the dose responses of more than 30 pigments and varnishes. It is generally accepted that a dose of $10 \mathrm{kGy}$ will not induce painting degradation, while insects and most fungi are killed $[178,181]$.

The consolidation of wooden samples by impregnation with resins, hardened by radiation polymerisation, is a specialist application that merits separate discussion. In this case, the disinfection is implicit and an important improvement in the mechanical strength of highly degraded wood may be obtained.

\section{PAPER}

The major threat to paper artefacts is from fungi. Increased humidity can easily activate fungal growth, which can spread rapidly. Some bacteria also affect paper and woodworms can damage collections of books with wooden covers. Other insects do not digest cellulose but are attracted by binding materials and contribute to the disintegration of books creating a premise for further micro-biological attack.

Paper is made from cellulose fibres but with no, or low, lignin content. Consequently degradation due to irradiation is an issue and solutions are difficult. At low irradiation doses the degree of cellulose polymerisation is reduced. See Figure 6.5. However, this is not reflected in the macroscopic properties of the paper. The determination of the irradiation dose is sensitive and should take into consideration the severity of the biological attack and the radiation resistance of the contaminants. A number of reports show no changes to paper properties (mechanical strength, colour, $\mathrm{pH}$, water sorption, etc.) for doses in the range of 5 to $10 \mathrm{kGy}$ [181-183].

\section{Textiles, leather and parchment}

Textiles can be equally affected by insects, fungi or bacteria. Micro-organisms (fungi) are the main threat for historical leather. Sometimes, insects (woodworms in the case of old book covers) are also destructive. Due to reduced water retention, parchment is more resistant to pest attacks but is generally fragile because of its age [184]. The lack of information on the irradiation effects on textile, leather or parchment artefacts can be attributed to the smaller quantities of such items. The selection of the irradiation dose should take into consideration each of the materials (cotton, wool, silk, leather, etc) and the extent to which the artefacts have already been degraded by biological attack [179].

\subsubsection{IRRADIATION CONSOLIDATION OF WOODEN ARTEFACTS}

Consolidation of wooden artefacts by impregnation with synthetic polymers, radiation polymerisation and/ or cross-linking is a field which involves both radiation physics and radiation chemistry. In the case of disinfection the only concern is to not have unwanted degradation of the materials; for consolidation a careful control of the chemical processes induced by radiation is essential. Dose, dose-rate, and concentration of reagents are all parameters which need to be controlled. Care also needs to be taken as exothermic reactions can lead to irreversible heat damage to artefacts.

Research on this topic started worldwide in the 1960s but the field was pioneered and first applied on a large scale in ARC-NUCLEART (Atelier Regional de Conservation), Grenoble, France [185].

Starting in 1970, NUCLEART have a long history of achievements for both radiation disinfection and radiation consolidation [186-188]: consolidation of the $19^{\text {th }} \mathrm{C}$. mosaic parquetry (flooring) of ancient Grenoble city hall (1970); disinfection of the famous Pharao Ramses II mummy from the Cairo Egyptian Museum (1977); disinfection of the baby mammoth Kroma, found in permafrost soil in Northern Siberia (2010). The works 
developed currently at NUCLEART include consolidation and restoration of a large number of religious items (e.g. statues) and very large wooden objects (e.g. furniture pieces).

\begin{abstract}
APPLICATION
The principle of consolidation is in many ways similar to methods for producing composites. A close contact between the material and the consolidation matrix is necessary. In case of cultural heritage artefacts, air or water is removed from the pores and micro-pores of the material and a liquid matrix is introduced. The procedure can be applied to various materials, but the best results are obtained with degraded wood. The weight of the object is increased by $50-100 \%$. $A$ range of different consolidant materials have been tried (monomers, pre-polymers) but the best results have been obtained using radiopolymerisation of polyester resins.
\end{abstract}

A special technique was developed at NUCLEART for waterlogged wood consolidation (e.g. parts of ancient Viking shipwrecks). Consolidation gives a new lease of life for highly degraded wooden artefacts and, in some cases, is the only practical preservation method (e.g. for waterlogged wood) $[179,187]$.

\subsubsection{GAMMA RAY TREATMENTS AT IRASM IFIN-HH}

$\mathrm{Y}$-irradiation treatments to preserve cultural heritage form an important project at the IRASM - Radiation Processing Centre of IFIN-HH. Experiments started 20 years ago, and large quantities of important cultural artefacts (wood, polychrome wood, paper, textiles, leather and parchment items) have been treated since then $[179,189]$.

One remarkable achievement was the irradiation of the iconostases from two Romanian historical churches [189]. See Figures 6.6 and 6.7. The treatment was reported as a success story by the International Agency for Atomic Energy (IAEA) in 2012. An economic study revealed that restoration of the iconostases costs only $10 \%$ of the price of producing new ones. A classical (chemical) disinfection treatment would have required years of work; whereas using radiation treatment the iconostases were fully restored in several months. For transport and irradiation, the large iconostases $\left(6 \times 4 \mathrm{~m}^{2}\right)$ were dismantled into pieces up to $2.5 \mathrm{~m}$ in size. Several collections, containing more than 400 icons, with sizes from $30 \times 40 \mathrm{~cm}^{2}$ to $150 \times 200 \mathrm{~cm}^{2}$ were also treated.

An extremely complex irradiation treatment was performed in the case of the "Theodor Aman" Museum, of the Bucharest City Museums network [179]. The building,

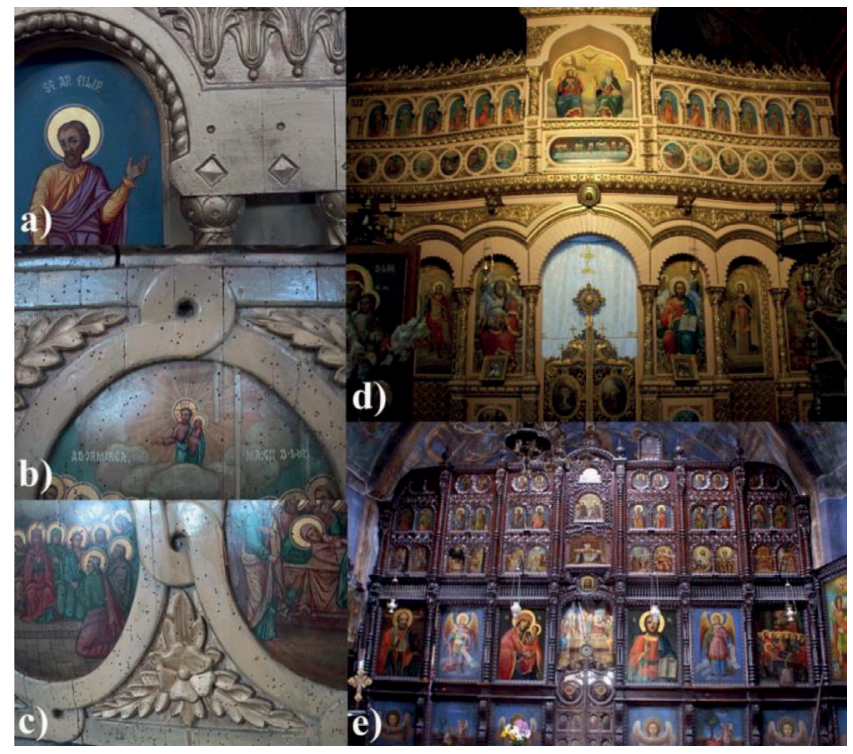

Figure 6.6: Iconostases from Izvoarele churches in Dambovitza county, Southern Romania: a), b) and c) details of parts of the iconostases, showing marks (holes) due to woodworm attack; d) and e) iconostases of the two churches after their complete restoration.

a temple of art in neo-classical and Renaissance style, suffered severe damage due to lack of care in recent years. The damaged roof produced advanced degradation of both the building structure and the collections it contained. When funding became available for a complete refurbishment of the building, a disinfection of its complete inventory was necessary.

The decision was taken to use radiation treatment. All the items from the Memorial museum (furniture, flooring, doors, wainscot panelling, wallpaper, tools and the personal items of the painter) were treated to remove woodworm and fungi. Today the museum is open to the public.

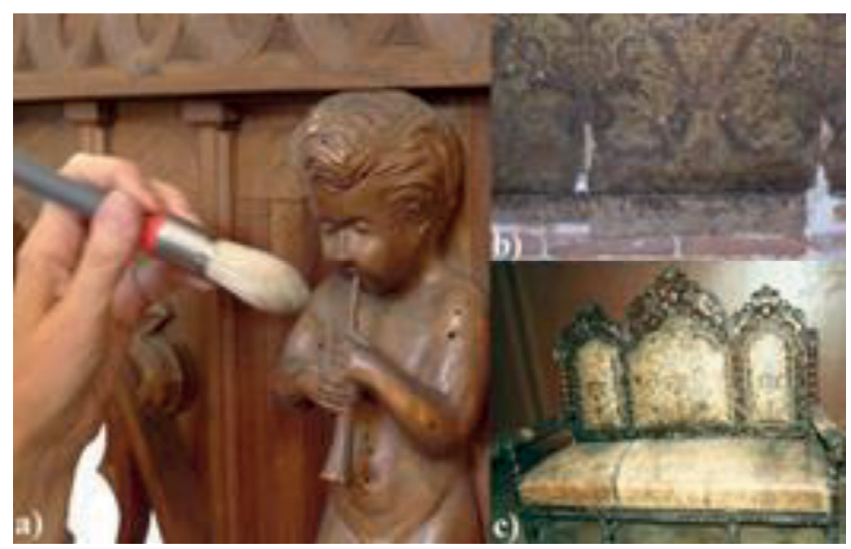

Figure 6.7: Items from the Theodor Aman Museum: a) detail of a cabinet with woodworms marks; b) and c) wallpaper and sofa with marks due to fungal attack.

Romanian painter (1831-1891) 


\subsubsection{IRRADIATION CONSOLIDATION OF WOODEN ARTEFACTS AT IRASM IFIN-HH}

Since 2012 co-operation with NUCLEART, Grenoble, France, has helped IRASM IFIN-HH to introduce irradiation consolidation methods to Romania. The first work was performed using test equipment designed for the consolidation of small items. See Figure 6.8.

Irradiation consolidation is an irreversible treatment which is sometimes controversial because it changes the original material. However, it gives new life to highly degraded items which are impossible to save using other preservation methods.

A first test of this technique was performed on a traditional wooden object: an old butter churn. Before consolidation, this churn could not support its own weight. After irradiation consolidation it gained more than $50 \%$ in weight and can now stand in an upright position. Consolidation was performed with a polyester-styrene mixture (NUCLEART method). After irradiation the styrene

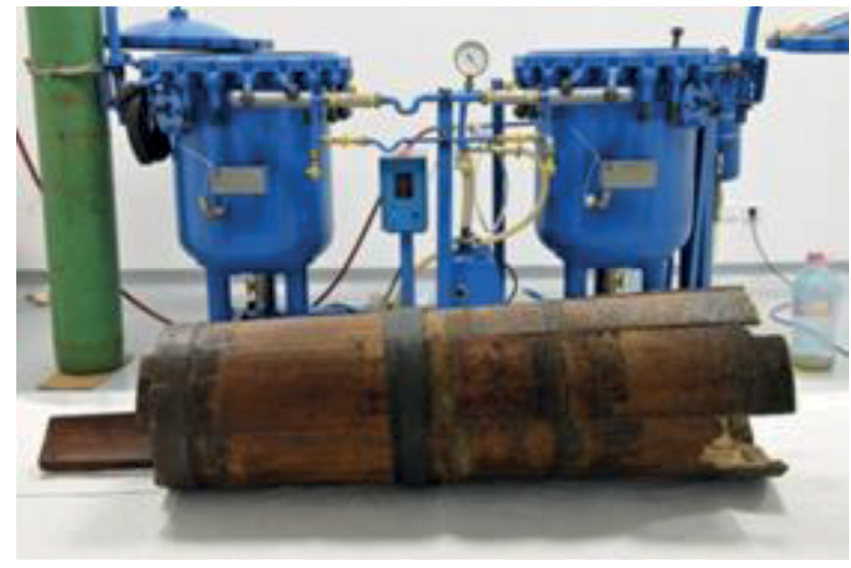

Figure 6.8: Test consolidation facility at IRASM IFIN-HH: 100 liter vacuum/pressure impregnation equipment (back); wooden butter churn degraded by woodworm atack and consolidated by radio-polymerisation (front).

formed bridges between the polyester chains and created a tri-dimensional molecular structure [188].

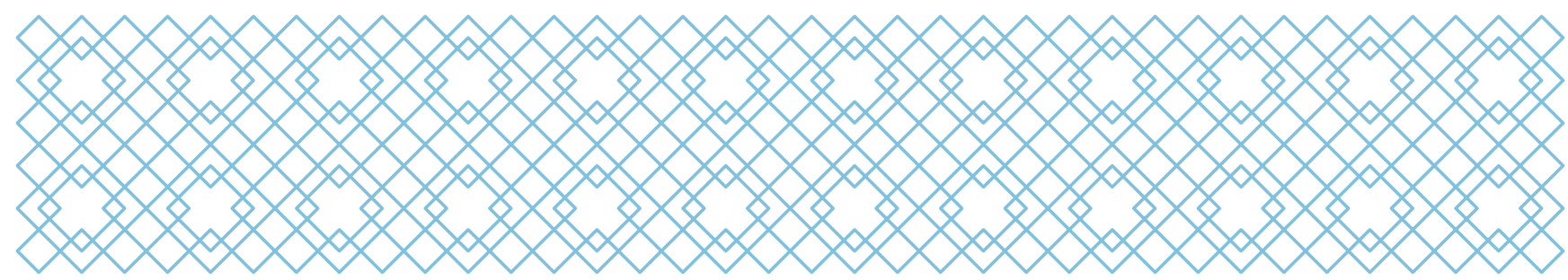

\section{CONCLUSION}

T he application of atomic and nuclear techniques to the study of archaeological objects gives the historian or archaeologist material information that can help them to understand life during ancient times. This knowledge is necessary to test the authenticity and provenance of artefacts and to prepare and carry out necessary restorations. All these objectives are common to a very large community of people working in the field of archaeometry, i.e. the "application of science to art and archaeology". For all these research activities a multi-disciplinary approach is essential, bringing together physicists, chemists, archaeologists, numismatists, historians, geologists and conservators from different laboratories, institutions and museums.

This topical paper, brought to you by the Nuclear Physics Division of the European Physics Society, provides a useful opportunity to show the public, and also the professional community, just how broad and important the field of application of nuclear techniques has become in the study of cultural heritage, its characterisation and preservation.

This publication reports the very fruitful collaboration of many scientists from different fields who are all focused on the same goal - to enlarge and deepen our knowledge about our cultural heritage and to keep it safe for future generations. 